\title{
ESPAÇOS INVENTADOS, A VERDADEIRA E ÚLTIMA FRONTEIRA? ALGUNS EXEMPLOS
}

Victor S. GONÇALVES ${ }^{1}$

Em memória de Orlando Ribeiro, que, ao visitar com Suzanne Daveau as minhas escavações em Vila Nova de S. Pedro, me explicou, tarde de mais, o que era a Faculdade de Letras de Lisboa em meados dos anos 80.

Só nos relatos de Marco Polo, Kublai Khan conseguia discernir, através das muralhas e das torres destinadas a ruir, a filigrana de um desenho tão fino que escapasse ao roer das térmitas. (...)

Os olhos não vêem coisas mas sim figuras de coisas que significam outras coisas: a tenaz indica a casa do arranca-dentes, a garrafa a taverna, a alabarda o corpo de guarda, a balança romana a ervanária. (...)

O atlas do Grão Khan também contém os mapas das terras prometidas visitadas em pensamento mas ainda não descobertas ou fundadas: a Nova Atlântida, Utopia, a Cidade do Sol, Oceana, Tamoé, Harmonia, New-Lamark, Icária.

Italo Calvino (2008), Cidades Invisíveis:

9-10, 17, 165

Recebido: Março 2015. Aceite: Julho 2015.

1 Victor S. Gonçalves é Professor catedrático da Faculdade de Letras da Universidade de Lisboa, onde fundou o Centro de Arqueologia (UNIARQ) e nele o Grupo de Trabalho sobre as antigas Sociedades Camponesas (WAPS). Conduziu também, desde 1974, todas as fórmulas dos cursos em Arqueologia. Para além de arqueólogo de campo, é um leitor militante de largo espectro e um adepto de Música (clássica, jazz e folk). Foi aluno, em disciplinas opcionais. de Orlando Ribeiro, Jorge Dias e Viegas Guerreiro. E-mail:vsg@campus.ul.pt 


\section{COMEÇANDO}

Não falando de Jules Verne, que é de uma outra liga, durante muitos anos, a literatura dita «ficção científica», em sentido estrito, publicou textos curtos, ilustrados com extra-terrestres maléficos, damas bem desenvolvidas e robots de apreciáveis dimensões. Este gosto por mulheres pulposas, aliens e maquinarias semi-humanas gigantescas, tem naturalmente que ver com a invenção de alternativas, mecanismos de compensação e os próprios medos das sociedades que saem profundamente danificadas de duas guerras mundiais devastadoras. $\mathrm{O}$ mesmo, ainda que não exactamente, acontece com a literatura dita «fantástica», que ressuscita histórias que vêm pelo menos desde a Idade Média, onde fizeram furor. Como, em Portugal, a de Briolanja, a menina dos leões... Há no entanto o cuidado de as localizar em épocas específicas, até mesmo em planetas diferentes ou galáxias distintas, muitas vezes acompanhadas pelo mito da Espada, seja ela de aço superior (Conan, que obtém a sua numa antiga Sepultura «megalítica», ou Excalibur, de origem incerta) ou de luz (Star Wars, claro, sendo naturalmente vermelha a cor dos maus, frequentemente péssimos...).

Mas onde ficam Ilhas, Continentes, Oceanos, Planetas, Sistemas Solares, Galáxias? Onde realmente se passaram coisas e situações, quer em tempos curtos, quer em outros, mais longos? Menoridades geográficas ou nem por isso?

O que Marco Polo contava a Kublai Khan existia mesmo assim, sem mapas ou ilustrações, apenas na memória do viajante? Ou nem sequer era preciso que existisse? Até que ponto o traçado de um Rio ou as fronteiras de um Oceano não podem ser terrivelmente decepcionantes na sua inevitável minudência?

\section{VIAGENS POR TERRA}

J. R. Tolkien (1892-1973) não apenas escreveu sobre o Mundo dos Hobbits, mas também sobre o do Senhor dos Anéis. Parecem o mesmo, mas talvez não sejam. No entanto, o Mundo a que se referem fisicamente é um só e as longas peregrinações, ou buscas, é nele, e só nele, que decorrem, ainda que a força das imagens diacrónicas desse Mundo seja notável e a sua Geografia mude com o passar do Tempo, perante o peso do Terror e da Ameaça que deslocam os centros de acção no decorrer da Viagem.

E toda uma Geografia implícita começa logo com a designação de Terra do Meio. Se há uma Terra do Meio há forçosamente duas outras, se esquecermos os lados. E não é apenas no sentido geográfico, mas também no metafórico, que a categoria conta. Equilíbrio e desequilíbrio. O Mundo dos Hobbits é um mundo de equilíbrio relativo, Paz e Alegria. Fora dele, ainda que longe, mora a Guerra e os reinos devastados de humanos, combatendo entre si, restos de antigas disputas, reacendidas pelo Mal.

E os filmes da saga, no inevitável merchandising que geram, produziram também Cartografia. Em blocos, agendas e tantos outros suportes. Alguns com notável finura de traço (fig. 1). 

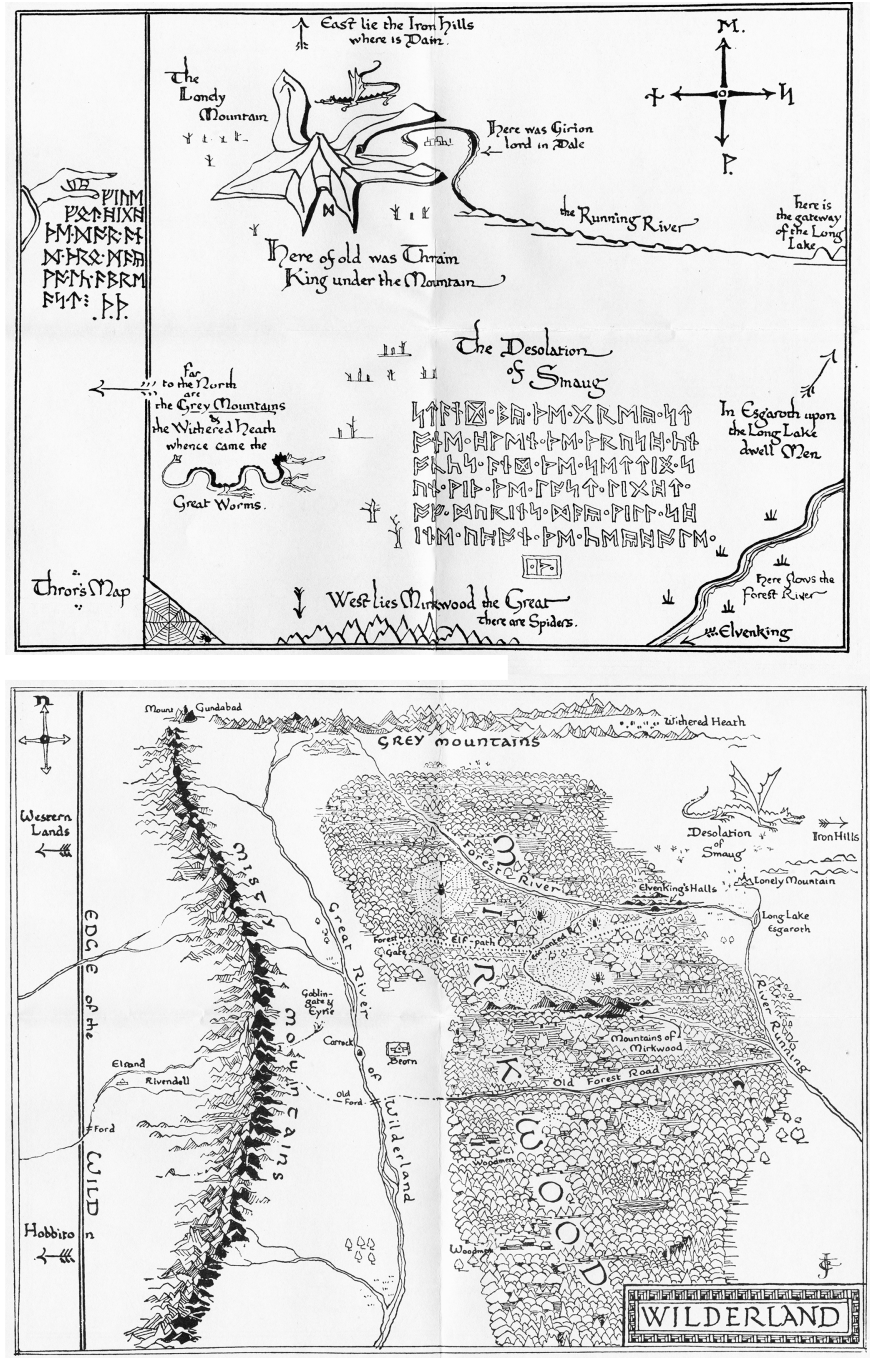

Fonte / source: Moleskine, Edição especial

Fig. 1 - Hobbit, The desolation of Smaug.

Contrariamente ao que uma Geografia optimista poderia fazer esperar, a progressão no espaço não é apenas rigorosa pelos riscos que implica, mas pelos obstáculos cada vez mais evidentes de uma paisagem cada vez mais desolada. E nem a eventual morte do Anel ameniza o gigantismo das muralhas ou dos seres ressuscitados pelo Mal.

Jack Vance (1916-2013), em O Ciclo de Tschaï (1968, 1969a, 1969b, 1970), reconstrói um Mundo que só tem um início, o local onde cai a nave que vem da Terra, e um fim, o sítio de onde o astronauta perdido voltará ao espaço e, esperamos que sim, porque bem o mereceu, ao planeta de onde partiu. 
O Ciclo de Tschaï não precisa de Geografia, é um percurso por categorias que envolvem a Terra, a da Superfície e a da Profundidade das cavernas, o Mar, o Ar e o Espaço interestelar. Tudo se toca e interpenetra, claro, mas não é isso que conta.

Vance foi um autor desconcertante, capaz de obras muito boas e de outras assim-assim. O seu gosto por deslocar a acção de uma trama única por vários planetas (ou absorver o espaço de um só, como no Planeta Gigante, 1951) torna as geografias impossíveis. Um herói único, muitos mundos. Cartografá-los ocuparia muito tempo.

Andy Weir (1972- ), tal como, ainda que menos, Pratchett, usa uma Cartografia com dados importantes, ainda que simplificados (fig. 2). No mapa que abre The Martian, 2011, aparece uma escala gráfica como as que nós usamos, e, logo na página seguinte, uma ampliação sectorial do mapa. Claro que provavelmente não iremos nunca à cratera Schiaparelli ocidental (nem à oriental...), e que a ampliação é absolutamente inútil, mas a convicção e o brilho merecem relevo. Como o humor, graficamente não representável, (p. 205 da tradução francesa):

- Venkat, acreditas em Deus, perguntou Mitch.

- Claro. Sou hindu. Acredito em muitos deuses.

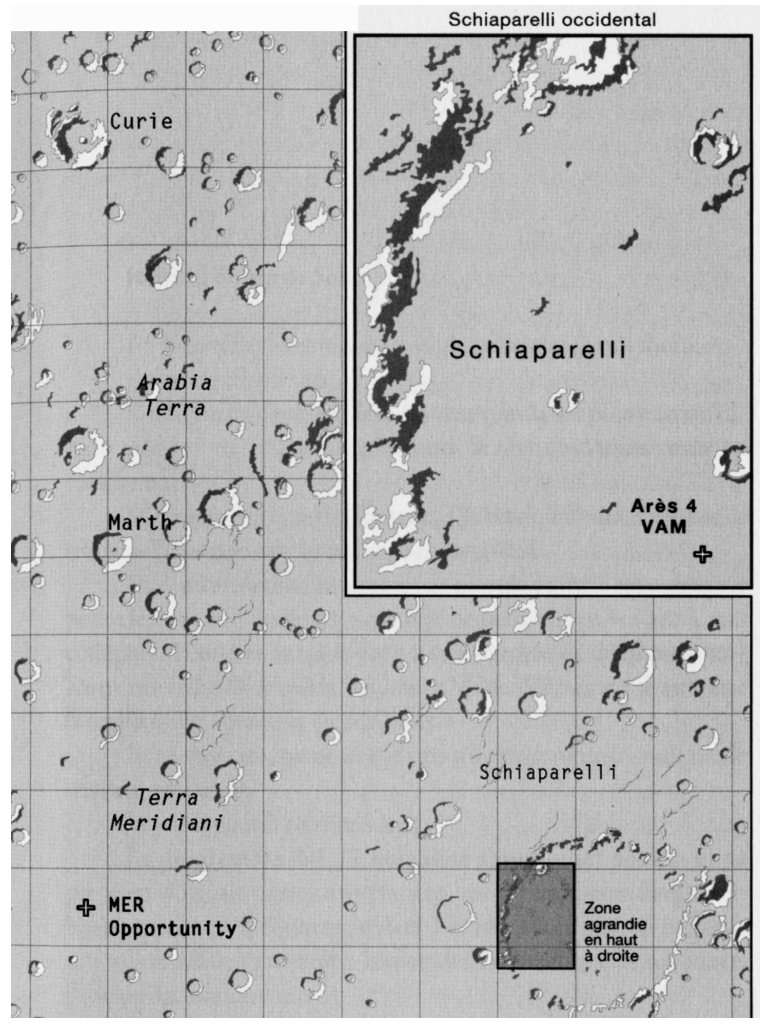

Fonte/source: The Martian by Andy Weir, 2011.

Fig. 2 - Cratera Schiaparelli em Marte.

Fig. 2 - Schiaparelli crater in Mars. 


\section{VIAGENS POR MAR}

Nos quase infindáveis Anais do Disco Mundo, Terry Pratchett (1948-2015), que acaba de morrer, produz uma grande reviravolta na história das relações entre Geografia e espaços inventados, ao publicar The Complete Ankh-Morpork (em francês: Tout Ankh-Morpork. Guide Touristique Exhaustif). E isto porque o nome do livro é inultrapassável em precisão. É mesmo um Guia Turístico, com uma Cartografia tão exacta como totalmente inventada. Tal como as cidades gémeas de Ankh e Morpork. Quanto ao texto, adopta um grafismo (e conteúdo) brilhantemente adaptado de almanaques antigos...

Chamo a atenção para a força e excelência da grande planta em desdobrável que acompanha o livro, do detalhe do original e mesmo dos pormenores ampliados, com coordenadas alfanuméricas (fig. 3), de uma carta com «prático» uso turístico, se Ankh-Morpork existisse e fosse visitável...

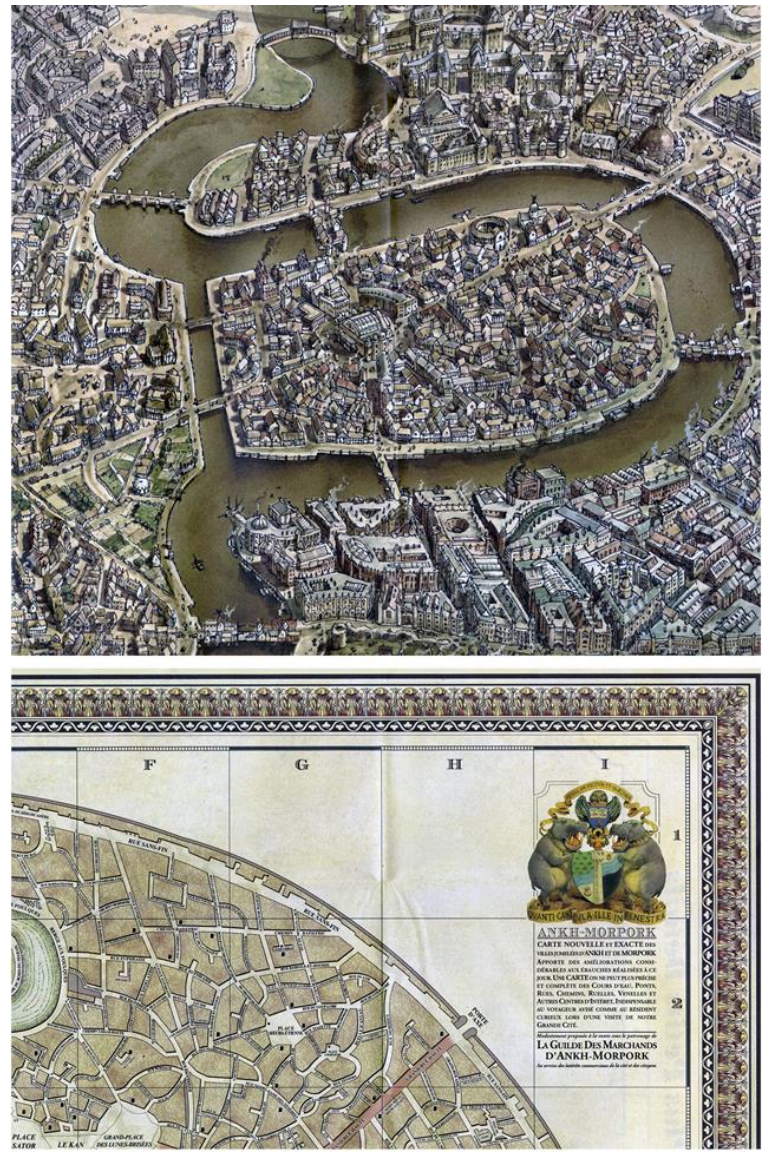

Fonte/Source: Terry Pratchett, 2012.

Fig. 3 - A cidade imaginária Ankh-Morpork.

Fig. 3 - Ankh-Morpork fictional city. 
Paul Kearney (1967- ), nos cinco volumes de As monarquias divinas (1995, 1996a, 1996b, 1999, 2002), adopta o sistema mais económico possível: o mesmo mapa para os cinco volumes. Mais uma vez, um Mar (o Grande Oceano Ocidental), rodeado por pequenas Ilhas e por pontas maiores ou menores de continentes. Uma pequena escala e uma elegante seta indicando o Norte. E muitas cordilheiras, pouco imaginativamente orientadas Nor-Noroeste...

Mas o Mar, uma das Mães da Cartografia clássica, está presente pelo menos em quatro das cinco capas dos volumes da edição monegasca (fig. 4). E não é claro que não esteja no quinto volume: é um Rio que vemos? Ou a ponta de um Oceano?
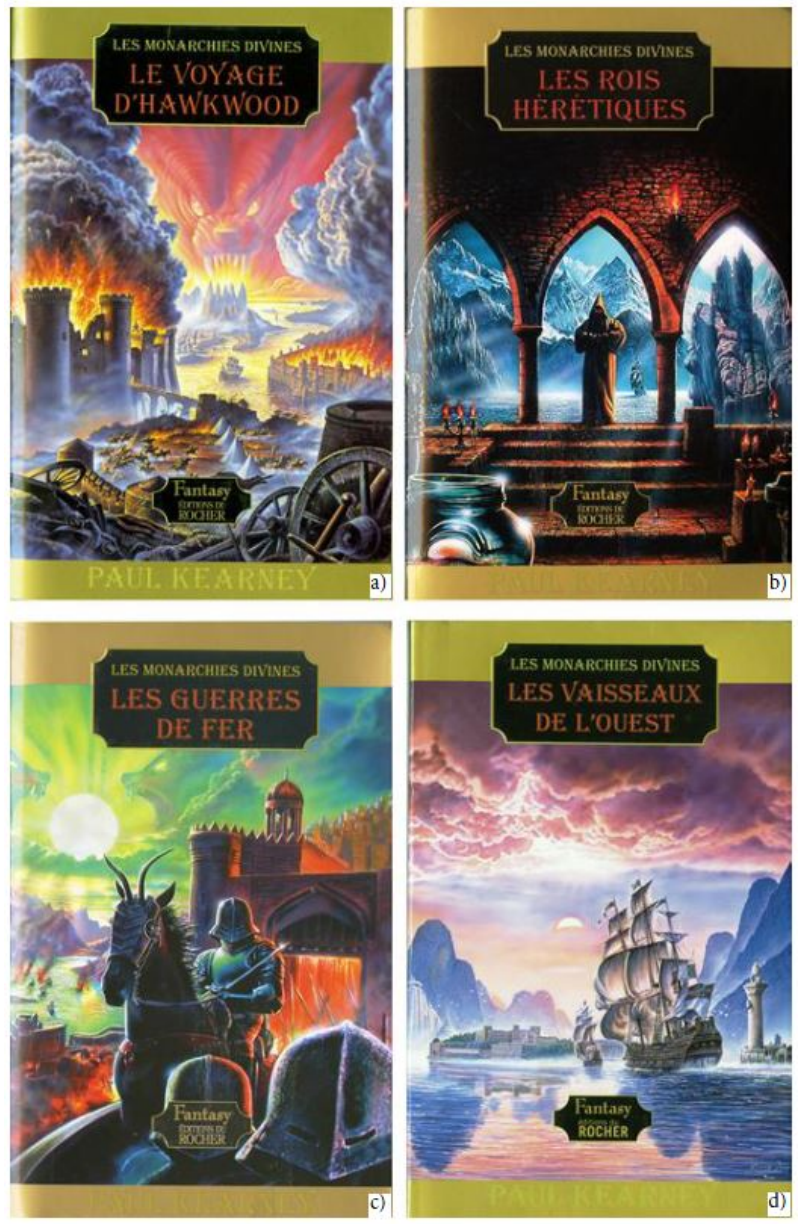

Fig. 4 - Quatro das cinco capas da edição monegasca de The monarchies of God:

O Mar (ou a água), um dos mitos urbanos da nova «Ficção Científica».

Fig. 4 - Four out of five covers of the Monegasque edition of The monarchies of God.

The sea (or the water) one of the urban myths of the new "Science Fiction".

a) vol. 1 (1995); b) vol. 2 (1996a); c) vol. 3 (1996b); d) vol. 5 (2002). 


\section{FANTASIA E FANTÁSTICO}

Jay Kristoff (n. ?), em Stormdancer, Kingslayer e Endsinger (The lotus war, 2012, 2013, e 2015) não se afasta da economia de detalhes detectada entre outras situações, ainda que a virtuosidade da sua escrita tenha muito a ver com a eficácia japonesa. Um steampunk a propósito de um arquipélago que recorda (e com razão) o Japão comprimido por uma tenaz? Numa Cartografia insular (fig. 5), tão ao agrado dos autores da nova Science Fiction, esta proveniente da execução brilhante de David Atkinson (handmademaps. com)? Outra coisa não seria de esperar. Só falta a espada, uma espada que hoje seria certamente do super-aço japonês VG-1 San Mai III, como a minha Kukri...

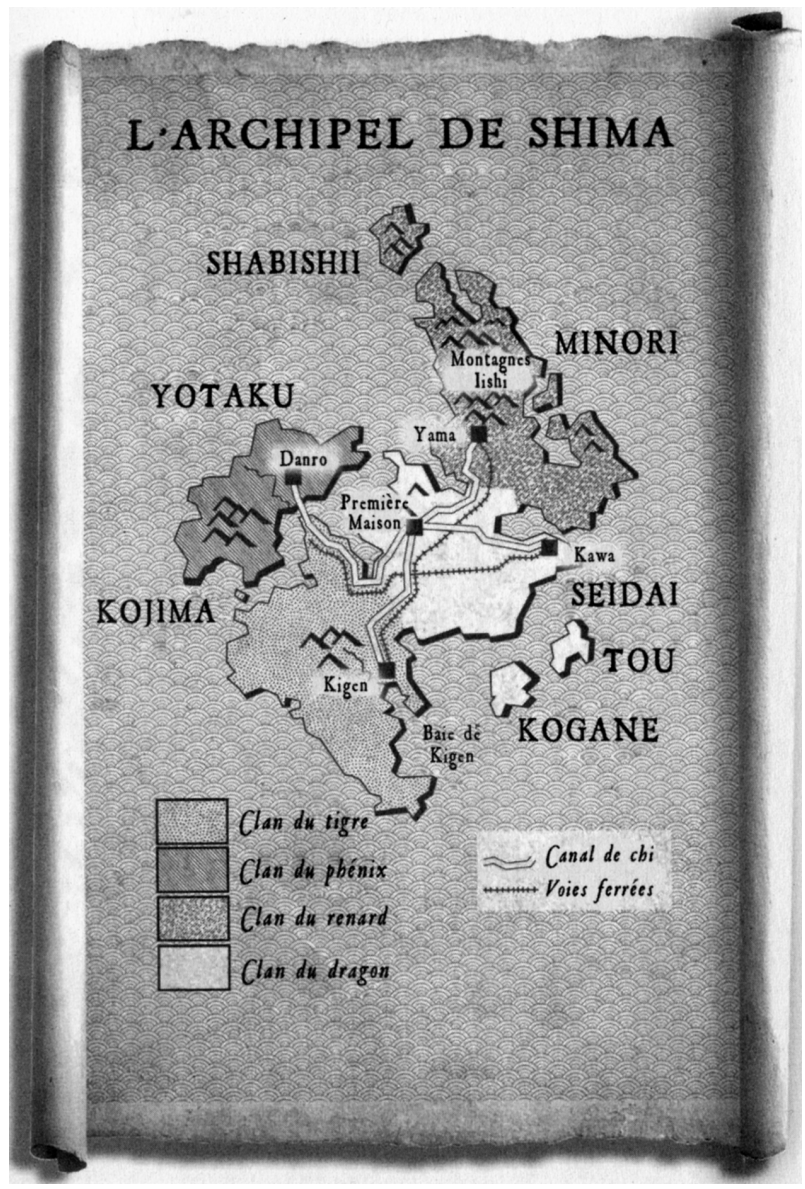

Fonte/Source: Kristoff, 2012

Fig. 5 - O arquipélago de Shima segundo Jay Kristoff. Jay Kristoff nasceu na Austrália... uma super-ilha...

Fig. 5 - Shima islands by Jay Kristoff. 
Scott Lynch (1978- ), na sua trilogia Les salauds Gentilshommes (2006, 2007, 2014), também vive de algum modo da água e da Geografia improvável. Basta ver o mapa (fig. 6) desenhado para Karthain (nome inspirado em Cartago?), logo a abrir o $3^{\circ}$ volume (2013). Dos estranhos cursos de água inventados só um deles desemboca no Amathel, o Lago das Jóias, um Lago com Ilhas bizarras.

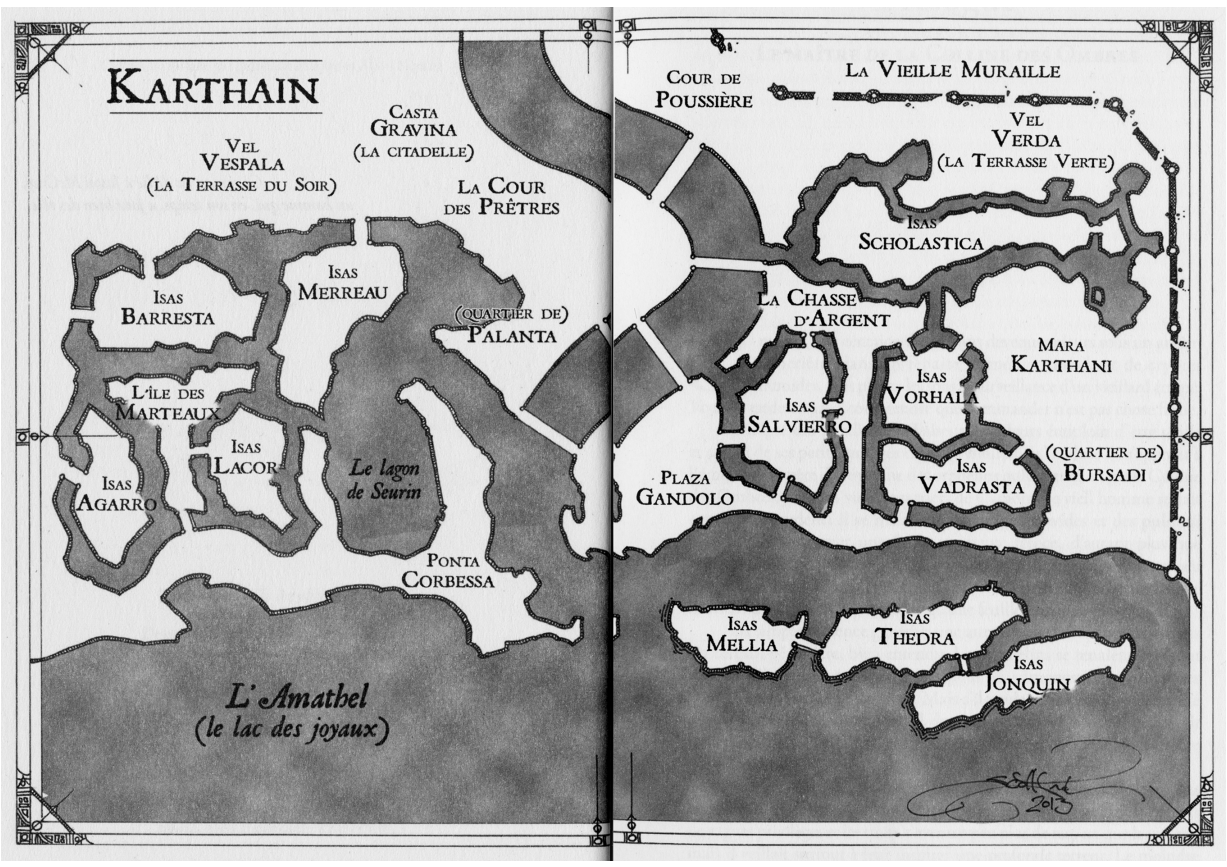

Fonte/Source: Scott Lynch, 2013-14

Fig. 6 - A improvável Geografia de Karthain.

Scott Lynch nasceu em St. Paul, Minnesota, uma cidade com um belo Rio...

Fig. 6 - The improbable Geography of Karthain.

\section{AHHH !! O ESPAÇO ??}

Tirando Ix, um planeta especializado em máquinas e armas (Herbert, 1965), cujos detalhes geográficos deveriam compreensivelmente ser mantidos em segredo, não há, surpreendentemente, grandes grafismos sobre os planetas governados pelo Padishah e idênticos super-líderes. E, sobretudo, o que seria ainda mais interessante, sobre as suas interligações espaciais. Sempre que há um Império no espaço, ou uma República confederada, como nos primeiros episódios de Star Wars, há ausências gráficas impressionantes e cada planeta por si. E com os muito úteis portais espaciais, espécie de Via Verde galáctica, então para quê cartografar? E é com alguma surpresa que ouvimos, em algumas 
séries, falar misteriosamente de «territórios não cartografados», quando ao longo dos episódios que se desmultiplicam não se vê qualquer aparelho preparado para registar simples crateras ou rios integrados referidos nos textos escritos. Na sua longa série sobre a «Cultura» (11 volumes, se incluirmos The Hydrogen Sonata), Ian M. Banks (1954-2013) descreve um outro tipo de associação planetária que nada tem que ver com isto. Mas que, sob outras perspectivas, é exemplar. E também incartografável.

Autores mais antigos, como Poul Anderson (1926-2001), Isaac Asimov (1920-1992), Lloyd Biggle Jr. (1923-2002), Ray Bradbury (1920-2012), Philip Dick (1928-1982), Robert Sheckley (1928-2005), Ursula Le Guin (1929-) ou outros, mais recentes, como Dan Simmons (1948-), Kim S. Robinson (1952-), Joe Scalzi (1969-), oscilaram entre algum espaço, sempre facilmente transponível, histórias de space opera e narrativas mais sólidas, e a criação de inexcedível beleza das Martian Chronicles (de Bradbury, obrigatória a leitura da versão inglesa) ou a prosa poética de Le Guin ou o génio de Philip Dick.

\section{PARA ALÉM DE TUDO}

O Rio que Orlando Ribeiro gostaria de ter fotografado só poderia ser o de Philip Jose Farmer (1918-2009). Aí temos a Geografia mais improvável, quando se fala do Mundo dos Mortos (Riverworld) como um percurso envolvente, em cujas margens todos acabaríamos por nos encontrar depois da morte (pensando em algumas criaturas que conheci, ao vivo ou por livros, mortas ou ainda vivas, só a perspectiva me aterroriza... e não pertenço ao grupo dos que se assustam facilmente...). É uma Geografia felizmente impossível.

Mas como representar um Rio que não conta por ele próprio, mas pelo «conteúdo»? Um Rio com 32 milhões de quilómetros, com margens povoadas por 40 mil milhões de ressuscitados?

Não é um Rio que é importante para Peter F. Hamilton (1960- ), mas mais uma vez a Água e o gosto pela representação de uma poeira de pequenas Ilhas na sua Cartografia (detalhe na figura 7, abertura da edição original, 2012). Hamilton nasceu perto do Rutland Water Park...

Uma palavra para Neil Gaiman (1960- ), um não-geógrafo militante, mas alternativo. American Gods (2001), de que há edição portuguesa, cria uma nova Geografia, a da emigração dos deuses para a América, levados pelos seus adoradores. A Geografia traduz aqui um processo de colonização (e de subsequente afrontamento) entre divindades arrancadas do seu contexto de origem e que se reorganizam em solo estrangeiro. Um livro a vários títulos notável. Dispensada Cartografia. Em Neverwhere, uma obra sombria, que cito por vezes e pela qual tenho verdadeira afeição, está subentendida a Geografia dos dois mundos, que se fundem às vezes, tal como na quase infantil série Torchwood, com a vantagem para aquela de uma excelente escrita... 


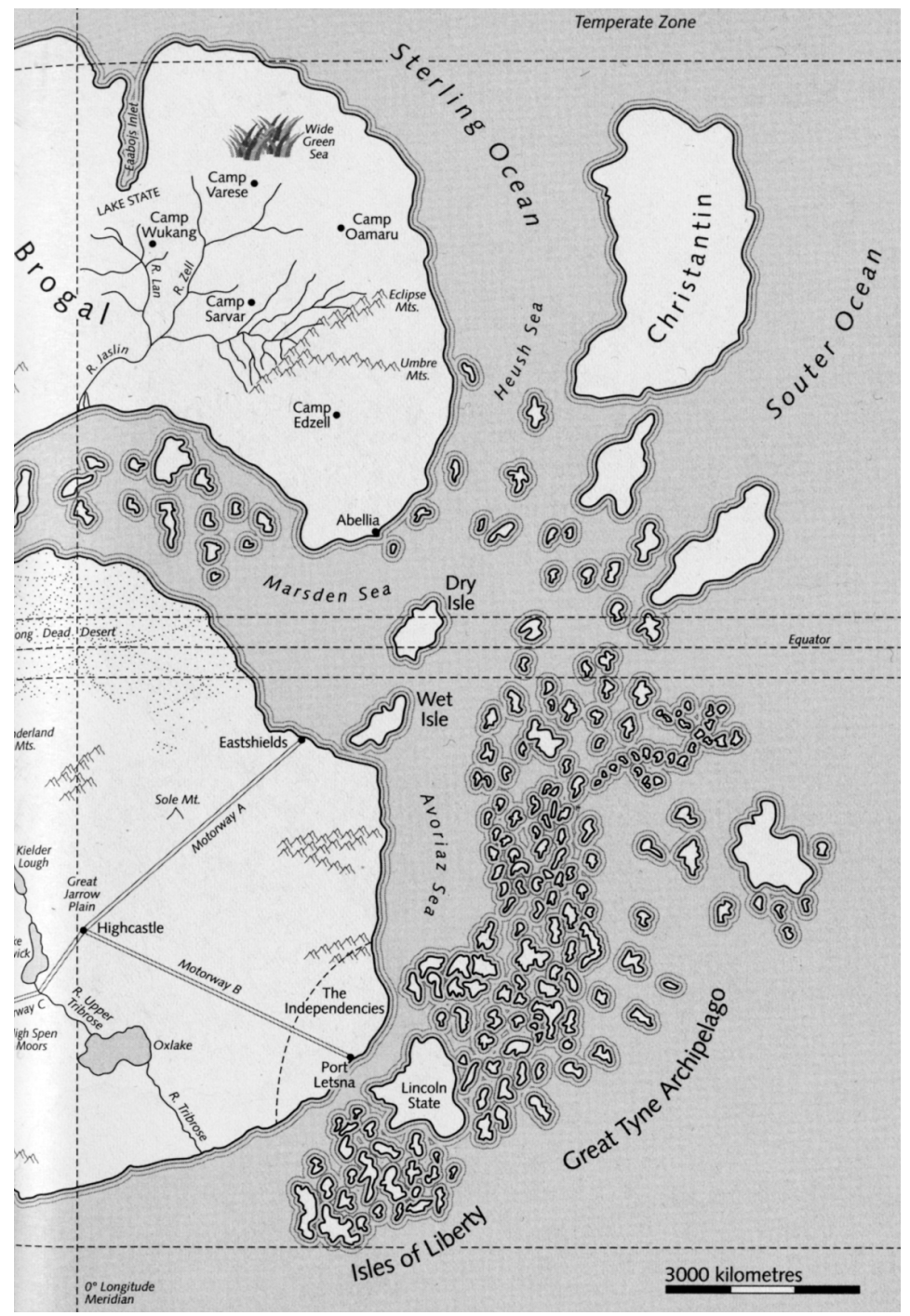

Fonte/Source: Hamilton, 2012, adaptado

Fig. 7 - The great North Road segundo Hamilton.

Fig. 7 - The great North Road by Hamilton.

Tal como em Arrakis, mais conhecido por Dune (1965), de Frank Herbert (1920-1986). A Guerra entre as Casas Harkonnen e Atreides passa-se no Espaço, mas sobretudo em Dune, um nome inspirado na verdadeira Mu Draconis, da Constelação Draco. Guerra controlada pelo Imperador Padishah, pela Guilda dos Navegadores e pelo Landsraad, numa subtil teia de manipulações. Cartografar esta complexa situação é quase impossível e Herbert não o fez. 
Acabo este curto texto, de escrita rápida, com a evidência do contraste: a Geografia e o seu contraponto gráfico, a Cartografia, são imprescindíveis, quando o são. E claro que nós, portugueses, devemos ter orgulho em Fernão Vaz Dourado, João Teixeira de Albernaz e tantos outros, que desenharam mapas e os ilustraram com contornos «verdadeiros» e figuras que nem sempre o eram. E orgulhosos tanto pela Geografia que sai de imagens de satélite, de alta resolução, como pela que inventou o Preste João, que pouco importa se existiu ou não...

\section{BIBLIOGRAFIA}

A primeira data indicada, sempre que disponível, é a da edição original, a segunda, entre parênteses rectos, a da tradução utilizada. No texto, as referências correspondem à edição original.

Banks, I. M. (2012). The Hydrogen Sonata. Londres: Orbit.

Bradbury, R. (1950). The Martian Chronicles. Special USA Edition.

Calvino, I. (1972 [2008]). As cidades invisíveis. Lisboa: Teorema.

Farmer, P. J. (1971 [1979]). Le Fleuve de léternité, 1: Le monde du fleuve. Paris: Pierre Laffont.

Farmer, P. J. ([1971]). Le Fleuve de l'éternité, 2: Le bateau fabuleux. Paris: Pierre Laffont.

Farmer, P. J. (1977 [1980]). Le Fleuve de léternité, 3: Le noir dessein. Paris: Pierre Laffont.

Farmer, P. J. (1980 [1982]). Le Fleuve de léternité, 4: Le Labyrinthe magique. Paris: Pierre Laffont.

Farmer, P. J. (1983 [1984]). Le Fleuve de léternité, 5: Les Dieux du fleuve. Paris: Pierre Laffont.

Gaiman, N. (2001 [2002]). American Gods. Paris: Au Diable Vauvert.

Gaiman, N. (1996 [2005]). Neverwhere. London: BBC Books; Headline Review.

Hamilton, P. E. (2012). Great North Road. Oxford: MacMillan.

Herbert, F. (1965 [1970]). Dune 1, Paris, Pierre Laffont.

Howard, R. E. (1932-1933 [2007]). Conan 1. Paris: Bragelonne.

Howard, R. E. (1934 [2008]). Conan 2. Paris: Bragelonne.

Howard, R. E. (1934-1935 [2008]). Conan 3. Paris: Bragelonne.

Kearney, P. (1995 [2004]). Les monarchies divines 1 Le voyage d'Hawkwood. Monaco: Éditions du Rocher Fantasy.
Kearney, P. (1996a [2005]). Les monarchies divines 2 Les rois hérétiques. Monaco: Éditions du Rocher Fantasy.

Kearney, P. (1996b [2005]). Les monarchies divines 3 Les guerres de fer. Monaco: Éditions du Rocher Fantasy.

Kearney, P. (1999 [2006]). Les monarchies divines 4 Le second Empire. Monaco: Éditions du Rocher Fantasy.

Kearney, P. (2002 [2007]). Les monarchies divines 5 Les vaisseaux de l'Ouest. Monaco: Éditions du Rocher Fantasy.

Kristoff, J. (2012 [2014]). Stormdancer. La guerre du Lotus 1. Paris: Bragellone.

Kristoff, J. (2013 [2015]). Kingslayer. La guerre du Lotus 2. Paris: Bragelonne.

Kristoff, J. (2015). Endsinger: The Lotus War 3. New York: Thomas Dunne Books.

Lynch, S. (2006 [2007]). Les salauds Gentilshommes. 1. Les mensonges de Locke Lamora. Paris: Bragellonne.

Lynch, S. (2007 [2008]). Les salauds Gentilshommes 2. Des Horizons Rouge Sang. Paris: Bragellonne.

Lynch, S. (2013 [2014]). Les salauds Gentilshommes. 3. La République des Voleurs. Paris: Bragellonne.

Pratchett, T. (2012 [2014]). Tout Ankh-Morpork. Guide Touristique Exhaustif. Nantes: L'Atalante.

Tolkien, J. R. R. (1937) The Hobbit. UK: George Allen \& Unwin.

Vance, J. (1968 [2001]). Le Cycle de Tschaï 1. Le Chasch. Paris: J'ai lu.

Vance, J. (1969 [1999]). Le Cycle de Tschaï 2. Le Wankh. Paris: J'ai lu. 
Vance, J. (1969 [1999]). Le Cycle de Tschaï 3. Le Dirdir. Vance, J. (1951 [2008]). Planète géante (Lintégrale). Paris: J’ai lu. Saint-Mammès: Le Bélial.

Vance, J. (1970 [1977]). Le Cycle de Tschaï 4. Le Pnume. Paris: J’ai lu.
Weir, A. (2011 [2014]). Seul sur Mars. Paris: Bragellone. 